\title{
On Sustainable Development of Modern Architecture Landscape Design
}

\author{
Yuqing $\mathrm{He}^{1}$, Rong $\mathrm{Nie}^{1}$ \\ ${ }^{1}$ China University of Geosciences, Wuhan, 430074, China
}

\begin{abstract}
Keywords: Construction. Landscape design. Sustainable development
\end{abstract}
\begin{abstract}
Based on the development of cities, landscape architecture design is growing all the time. Landscape forms are no longer confined to the simulations of nature, landscape is no longer considered a supporting role. However, we should be aware of the building and the surrounding environment is still difficult to achieve harmony and integrity of the system itself, so we should commit ourselves to sustainable development of modern architecture landscape design. This paper analyses the relationship between contemporary architecture and landscape design, and introduces the basic concepts of contemporary architecture, landscape design, and elaborates the content of sustainable development of landscape architecture design, and put forward the realization of sustainable development of landscape architecture design strategies.
\end{abstract}

\section{Introduction}

Construction is an important symbol of human civilization development, and the landscape is an indispensable part in architectural design system, it plays a very important role in improving and promoting the construction of ecological system in sustainable development. With the development of modern society, people tend to have more requirements for architectural landscape and space. Outstanding architectural design, will not only highlight the distinctive features of a city, but also improve the overall image of the city, is an important cornerstone for better development of the city. So, how to implement first-class architectural landscape design deserves to be explored.

\section{The relationship between contemporary architecture and landscape design}

Construction cannot exists all by itself, but coexist with natural and artificial elements, landscape of initial meaning is refers to human civilization traces, and modern landscape design comes with the development of industrial revolution and social development, it begins in the late 19th century United States, it advocates the return to nature. In the midst of a series of building systems design, it should be set off from building's characteristics, architecture and landscape design can closely combine, so as to gradually develop into a complex combination of environmental art, landscape art and urban design. In the eyes of designers, landscape architecture is the object the reappearance and expression, is equal to landscape. Landscape architecture design is an art, and combination of architectural design, landscape design, thus forming a landscape architecture as the main guide, combining architecture, planning and landscape.

\section{The Basic ideas of contemporary landscape architecture design}

\section{In accordance with the idea of people-oriented architectural landscape design}

People-oriented thinking comes from the West, it make people's interests and needs as a key element of consideration of all the issues, and as a judge. This requires the attention from architectural landscape designers. People's material and spiritual requirements build a basic starting point for architecture, a people-oriented landscape design perspective. Under the guidance of this philosophy, building integrated landscape designs should reflect systematic and functional coherence, not only to emphasize modern development, but also focused on sustainable development of natural and environmental resources in order to achieve harmonious development between man and nature. 
Through deep and comprehensive care, give people a sustainable living environment, this is the real people-oriented thinking.

\section{Respecting the traditional architectural landscape design ideas}

Architectural landscape design is not only an art, but also as an important carrier of history and culture. Surviving building is certainly closely related to the humanities, such as economic and social, can embody the integration between the spiritual and material life. How can we show the value of traditional architecture? For simple ports of traditional symbols or simple imitating of Western design style can only retained only on the visual level, and cannot raise the influence of the city. Architectural landscape design should not just stay on the surface, but the city's historical and cultural content should be amended, by setting up regional cultural symbols to set the city features, implementation, art created on the basis of the practical measures to prevent any simple make-up.

\section{Advocating the construction landscape ecological design concept}

Architectural landscape design appears with the modern industrialization and post-industrial age. Starts from harmonious industry to Garden City development, from eco-city construction to sustainable development city, it all represents the pursuit of nature, culture, environment, life, form of beauty and ecological functions. Architectural landscape design is mainly from the ecological point of view, and coexists with nature. The key to ecological landscape design is the regeneration of internal resources. Based on the building's existing organizational structures, in the perspective of history and landscape ecology, by making full use of new technologies and new materials, to reform existing space and structure, and endows it with great vigor. For example, Germany's Aimushe Park is the architect through the conversion of old industrial areas and old mining buildings, so as to build a modern Entertainment Park. This has not only enabled the continuation of the history, but also saves resources effectively, to achieve social, economic, cultural and emotional consistency of artistic value.

\section{Contents of the sustainable architecture landscape design development}

\section{Make sure regional characteristics of architecture plays a prominent role in landscape design}

City is composed of the various construction groups. After people came to a city, the first impression comes from the city's architectural landscape. Therefore, high quality architectural design, can greatly improve the city's environment, especially in medium and small cities, the situation is becoming increasingly significant. Architectural aesthetics should abide principles of organizational design, thus the city as an organic whole, and created the overall clear construction landscape structure. This requires an architectural designer of the landscape design treat each visual elements as an important foundation for building architectural landscape, use systematic ways of thinking landscape architecture development be visually coherent overall. Meanwhile, each medium and small city is formed at specific geographical natural, social and economic environment, rich humanities and history accumulation has become medium city's unique features, only from residential form, we can tell the geographical difference only by building material and building form, and medium city's ecological landscape can only use small scale change to show the sustainable development.

\section{Scientifically designed residential area to showcase the great value of building landscape environment}

In landscape architecture, residential area occupies a significant proportion, for residential design is to a considerable extent affect the coherence between itself and the surrounding landscape, thus affecting the modern architectural appreciation of landscape values. Now, however, the developer tends to consider their own interests, tend to select construction can only meet bright sunshine space, as a result, it cannot improve the architectural landscape planning and layout, and also looked lifeless and stiff. Residential environment mainly comprised by households in small gardens, groups and public venues. Space more often intertwining with each other and form the basis of materiality of the external environment of residential district. Planning and design of residential areas often constitutes an important basis for the external environment, in the design process of a residential area, in order to 
create a more rational civic combo, which will not only provide a better spatial scales of the external environment, but also are important prerequisites for access to quality landscape values. Landscaping of the main residential areas are made up of people, facilities, construction, landscaping, water bodies, as well as sketches and other environment in which the entity elements coupled with common historical, cultural, spiritual and cultural factors. Among them, the human factor is very important, once you lose this elements, other elements also loses the meaning. Landscape architecture are ornamental objects, their value is mainly reflected in whether landscape can meet the aesthetic value, and the landscape are the main people involved in activities, on their values reflected in the spirit of the place. Site is an important medium for communication and exchange, community consists of time, space, facilities and activities, and gives the corresponding meaning. Significance of places is more important than a single physical space; it is the soul of space. Outdoor spaces in the community, each space shall have suitable public activities and possibility of ambiguity. Place in modern society is where they can know themselves, when a lot of appreciators feel the same way, you get connected together, which was the scene of the collection. At the time when architectural design requires effective integration into the surrounding landscape, should give high priority to sustainable development of landscape architecture. To this end, the concept of effective combination of green building design, and in many aspects of building energy consumption dropped to its lowest level, it will gain more benefits in the long term.

\section{The design strategies for the sustainable development of architecture landscape}

\section{The scientific and rational mind to control forming of architectural landscape}

Architectural landscape design forming process is actually the scientific justification and implementation of landscape design; it is a rational use of the landscape. Scientific landscape architecture should be generated on a number of factors such as economic, ecological, and technical implementation of rigorous logic and reasoning, and buildings surrounding geology and geomorphology, climate, such as vegetation, biological as well as ground-implementation analysis of the vertical, area of the patch, corridor and the matrix implementation-level analysis, site suitability and functional positioning. The conclusion by the above mentioned argument can serve as a main basis for implementing architectural landscape design, it can also provide basis for landscape architecture design decisions. However, in our country's architecture, landscape design, explains personal aesthetic complex of traditional landscape design work remains, however, objective design without considering the reality is everywhere. Only learned the surface of Western architectural landscape design, but in fact that no one can really appreciate the deeper scientific reason.

\section{Find the depth of landscape design}

At present, the architectural practice of landscape design in China is still at a very early period of development, the development and perfection of landscape architecture discipline is not enough, design concept continues to stay on the surface landscaping, landscape architecture design level varies greatly, especially the blind copy. Architectural landscape design may be able to become the current approach that could be taken at this stage, allowing architectural landscape design is no longer just a simple decoration with a flattened extends, not to simply cover the vulnerability, but through architectural analysis, policy making and aesthetic characteristics of design methods to create a landscape. To apply architectural way of thinking to create differentiated functionality at all levels, through scientific and standardized forms, combine square, surrounding buildings and public facilities, thus becoming the systematic building of landscape environment. To be implemented by means of building landscaping ideas. Implementation of landscape processes, complexity and technical often affected the architectural landscape of ideas; architectural implementation relies on visual landscape in building support and technical support. One is through building technology to enhance the landscape. Landscape tended to have many improvements, but will face questions of how to improve it. Traditional green landscape is difference from modern architecture's, it combines technology and art. Therefore, technology should be the main method to make landscape architecture. Modern techniques can extend the architectural landscape imagination, as well as bring creativity for 
architectural landscape. The second is use architectural thinking to solve architectural landscape constraints. Architectural landscape often encountered many constraints, mainly consisted of site constraints, as well as the economic constraints. Landscape architecture design process, should use architectural way of thinking, to solve a large number of restrictive issues. For example, the seam zone difficult to achieve modal landscape of a building, or do not have the conditions for plant growth, but with functional space and can also learn from the study of architectural thinking method, select the most economical and applicable principles so as to solve architectural design problems. For example, high density narrow area in the buildings set enabling you to use divided color spray to the surface in the form of access roads, pedestrian and roadway, road, not only meet the functional demands of the road, but also provide residents with abundant visual appreciation of the object. This the simplest and most economical design method of architectural landscape design thinking actually embodied.

\section{Concluding remarks}

In General, the architecture landscape is a combination of building one's own culture, view and history. We are actively seeking to stand in the history of the new height and shape the landscape architecture design of sustainable development, in order to achieve harmony between man and man, between man and nature, harmony between the past and the future. With this in mind, to explore the architectural landscape design process, adhering to the philosophy of science, committed to creating the most beautiful and most hematic landscape.

\section{References}

[1] Liu Wei, Urban Planning and Architectural Design, Science and Technology Innovation Herald, 2009 (2).

[2] Yang Xirong, Discussion on Landscape Design at the Principles of Sustainable Development, Management Observation, 2009 (36).

[3] Ren Tingting, Wang Rongjie. Analysis on the Greening of Urban Residential Area, China New Technology and New Products 2010 (13).

[4] Liu Jin, Analysis on Green Construction Landscape Design, Housing Technology, 2012 (8).

[5] Li Xin, Several Reflections on Architectural Landscape Design, Urban Architecture, 2013 (6) 